\title{
Stress and steroid regulation of synaptic transmission: from physiology to pathophysiology
}

\author{
Nicola Maggio $^{1}{ }^{*}$, Harmen J. Krugers $^{2}$ and Menahem Segal ${ }^{3}$ \\ ${ }^{1}$ Department of Neurology, The Chaim Sheba Medical Center, Tel HaShomer, Israel \\ 2 Swammerdam Institute for Life Sciences, University of Amsterdam, Amsterdam, Netherlands \\ ${ }^{3}$ Department of Neurobiology, The Weizmann Institute of Science, Rehovot, Israel \\ *Correspondence: nicmaggio@gmail.com
}

Edited by:

Egidio D'Angelo, University of Pavia, Italy

Reviewed by:

Egidio D'Angelo, University of Pavia, Italy

Upon exposure to stressful experiences, steroid hormones, neurotransmitters, and neuromodulators are released which modulate specific processes in the brain. While the release of these compounds is believed to promote behavioral adaptation to stressful experiences, they have also been implicated in stressrelated psychopathology. Extensive research in the past decade has culminated in a deeper understanding of the cellular and molecular mechanisms of how stress hormones, neurotransmitters, and neuromodulators, alone and in concert, affect the brain. This new multidisciplinary approach involving behavioral, electrophysiological, molecular, and epigenetic studies is used to elucidate the long-lasting complex effects of stress on cognitive functions in the brain. The target for the action of these mediators ranges from membrane receptors to nuclear receptors, often specific for different brain areas, affecting eventually homeostatic and various cognitive functions.

In this Frontier Research Topic, we have put together chapters written by leaders in the field that provide up-to-date summaries of the different angles of work on the effects of steroid hormones, neurotransmitters, and neuromodulators on synaptic transmission and plasticity from ion channels to pathophysiological processes. The different chapters deal with epigenetics
(Hunter, 2012), which details the different nuclear targets for the long-term effects of stress. Mody and Maguire (2012) discuss the role of GABA in the feedback regulation of steroid action, Levy and Tasker summarize the current knowledge on the regulation of the HPA axis (Levy and Tasker, 2012). The main section of the Frontier Topic involves novel views on postsynaptic effects of steroid hormones, $\mathrm{CRH}$, and noradrenaline on synaptic functions in the brain. These include a section on amygdala-hippocampus interaction (Li and Richter-Levin, 2012), cellular, and molecular studies on CRH effects in the hippocampus (Chen et al., 2012), effects of early life stress on metabolic functions in the brain (Bock et al., 2012), interactions between noradrenaline and corticosterone on brain function (Krugers et al., 2012), region selective effects of corticosterone in the hippocampus (Maggio and Segal, 2012), and finally, effects of corticosterone on NMDA receptor function in the hippocampus (Tse et al., 2012). Finally, a behavioral study on the interaction between gestational and adult stress (Walf and Frye, 2012) concludes the list.

Altogether, these papers provide state-of-the-art insights how stress determines cellular and network function and ultimately how stress affects cognition and emotion in the brain, a subject of increasing importance in modern society.

\section{REFERENCES}

Bock, J., Riedel, A., and Braun, K. (2012). Differential changes of metabolic brain activity and interregional functional coupling in prefronto-limbic pathways during different stress conditions: functional imaging in freely behaving rodent pups. Front. Cell. Neurosci. 6:19. doi: 10.3389/fncel.2012.00019

Chen, Y., Andres, A. L., Frotscher, M., and Baram, T. Z. (2012). Tuning synaptic transmission in the hippocampus by stress: the CRH system. Front. Cell. Neurosi. 6:13. doi: 10.3389/ fncel.2012.00013

Hunter, R. G. (2012). Epigenetic effects of stress and corticosteroids in the brain. Front. Cell. Neurosci. 6:18. doi: 10.3389/ fncel.2012.00018
Krugers, H. J., Karst, H., and Joels, M. (2012). Interactions between noradrenaline and corticosteroids in the brain: from electrical activity to cognitive performance. Front. Cell. Neurosci. 6:15. doi: 10.3389/fncel. 2012.00015

Levy, B. H., and Tasker, J. G. (2012). Synaptic regulation of the hypothalamic-pituitary-adrenal axis and its modulation by glucocorticoids and stress. Front. Cell. Neurosci. 6:24. doi: 10.3389/fncel.2012.00024

Li, Z., and Richter-Levin, G. (2012). Stimulus intensity-dependent modulations of hippocampal long-term potentiation by basolateral amygdala priming. Front. Cell. Neurosci. 6:21. doi: 10.3389/ fncel.2012.00021
Maggio, N., and Segal, M. (2012). Steroid modulation of hippocampal plasticity: switching between cognitive and emotional memories. Front. Cell. Neurosci. 6:12. doi: 10.3389/fncel. 2012.00012

Mody, I., and Maguire, J. (2012). The reciprocal regulation of stress hormones and GABAA receptors. Front. Cell. Neurosci. 6:4. doi: 10.3389/fncel.2012.00004

Tse, Y., Bagot, R. C., and Wong, T. (2012). Dynamic regulation of NMDAR function in the adult brain by the stress hormone corticosterone. Front. Cell. Neurosci. 6:9. doi: 10.3389/fncel.2012.00009

Walf, A. A., and Frye, C. A. (2012). Gestational or acute restraint in adulthood reduces levels of $5 \alpha$ reduced testosterone metabolites in the hippocampus and produces behavioral inhibition of adult male rats. Front. Cell. Neurosci. 6:40. doi: 10.3389/fncel.2012.00040

Received: 15 November 2012; accepted: 26 December 2012; published online: 17 January 2013.

Citation: Maggio N, Krugers HJ and Segal M (2013) Stress and steroid regulation of synaptic transmission: from physiology to pathophysiology. Front. Cell. Neurosci. 6:69. doi: 10.3389/fncel. 2012.00069

Copyright (C) 2013 Maggio, Krugers and Segal. This is an open-access article distributed under the terms of the Creative Commons Attribution License, which permits use, distribution and reproduction in other forums, provided the original authors and source are credited and subject to any copyright notices concerning any third-party graphics etc. 